\title{
On lumped-reduced reaction model for combustion of liquid fuels
}

\author{
Yang Gao ${ }^{1}$, Ruiqin Shan ${ }^{1}$, Sgouria Lyra ${ }^{2}$, Cong $\mathrm{Li}^{1}$, \\ Hai Wang ${ }^{3}$, Jacqueline H. Chen ${ }^{2}$, Tianfeng $L u^{1} *$ \\ ${ }^{1}$ Department of Mechanical Engineering, University of Connecticut, Storrs, CT 06269, USA \\ ${ }^{2}$ Combustion Research Facility, Sandia National Laboratories, Livermore, CA 94550, USA \\ ${ }^{3}$ Department of Mechanical Engineering, Stanford University, Stanford, CA 94305, USA \\ *Corresponding Author Email: tlu@engr.uconn.edu
}

\begin{abstract}
A systematic approach to developing compact reduced reaction models is proposed for liquid hydrocarbon fuels using $n$-dodecane and $n$-butane as the model fuels. The approach has three elements. Fast fuel cracking reactions are treated by the quasi-steady state approximation (QSSA) and lumped into semi-global reactions to yield key cracking products that are $\mathrm{C}_{1}-\mathrm{C}_{4}$ in size. Directed relation graph (DRG) and sensitivity analysis reduce the foundational fuel chemistry model to a skeletal model describing the oxidation of the $\mathrm{C}_{1}-\mathrm{C}_{4}$ compounds. Timescale-based reduction using, e.g., QSSA, is then employed to produce the final reduced model. For $n$-dodecane, a 24-species reduced model is derived from JetSurF and tested against the detailed model for auto-ignition, perfectly stirred reactors (PSR), premixed flame propagation, and extinction of premixed and non-premixed counterflow flames. It is shown that the QSSA of fuel cracking reactions is valid and robust under high-temperature conditions from laminar flames, where mixing is controlled by molecular diffusion, to perfectly stirred reactors, which correspond to the limit of strong turbulent mixing. Bifurcation analysis identifies the controlling processes of ignition and extinction and shows that these phenomena are insensitive to the details of fuel cracking. To verify the applicability of the above finding to turbulent flames, 2-D direct numerical simulation (DNS) of a lean turbulent premixed flame of $n$ butane/air with Karlovitz number of 250 was carried out using a reduced model developed from USC-Mech II. The results show that QSSA for fuel cracking remains valid even under intense turbulence conditions. Statistical analysis of the DNS data shows that fuel cracking is complete before the flame zone, and for the conditions tested, turbulent transport does not bring any significant fuel molecules into the flame zones, thus further substantiating the validity of the approach proposed.
\end{abstract}

Keywords: model reduction; lumped fuel cracking reactions; bifurcation analysis; direct numerical simulation; $n$-dodecane; $n$-butane 


\section{Introduction}

Practical engine fuels typically contain a large number of components with wide varying molecular structures. In addition to the multicomponent nature, the high complexity of practical fuel combustion chemistry is also attributed to the myriad intermediate species generated during the pyrolysis and oxidation processes. While developments employing detailed modeling and surrogate fuel approaches are advancing rapidly, challenges abound in the application of the chemistry model in turbulent flame simulations. Both the underlying chemical complexities, which lead to model inaccuracy, and the large model size, which imposes infeasible computational expense, are some of the fundamental factors that limit the broader utilization of the chemistry efforts.

Fuel cracking is slow and rate-limiting at low-temperature conditions, and thus typically needs to be resolved [1-3]. However, fuel cracking through beta-scission occurs rather fast at high temperatures compared to the subsequent oxidation of the resulting small molecules. In a previous work, You et al. [4] examined the reaction chemistry of $n$-dodecane combustion under a wide range of conditions. The primary conclusion of that study is that in high-temperature (highT) combustion, $n$-dodecane undergoes complete pyrolysis, yielding methane, ethylene, propene, butene, and molecular hydrogen, before these smaller molecular weight fragments are oxidized. The oxidation of these fragments is rate-limiting for all conditions tested. These conclusions are consistent with experimental observations made later in shock tubes $[5,6]$. For these reasons, the fuel cracking processes may be approximated by a few semi-global reaction steps [4], which can subsequently be grafted on to a detailed $\mathrm{C}_{1}-\mathrm{C}_{4}$ model core, e.g., the USC-Mech II [7], to obtain compact hybrid models for high-T combustion $[4,8]$. The resulting models can further be reduced [9]. For instance, a 24-species reduced model was developed from a version of JetSurF 
with lumped fuel cracking reaction steps [8] using directed relation graph (DRG) [9-11], DRG aided sensitivity analysis (DRGASA) [12, 13], and linearized quasi-steady state approximations (LQSSA) [14], and was applied in direct numerical simulations (DNS) of a turbulent counterflow n-dodecane spray flame [15].

Nevertheless, in the work of You et al. [4], most of the combustion properties considered are those with negligible back mixing of burned or unburned mixtures. What was also not adequately studied was the near-limit phenomena, notably the extinction and ignition states in

perfectly stirred reactors (PSR), which are typically turning points of the $S$-curve response [16]. In the present study, we investigate the potential of using combined hybrid model development and model reduction to obtain highly efficient reduced models with less than 30 species for large hydrocarbon fuel combustion at high-T conditions. First, this hybrid model is assessed using the 24-species reduced model for $n$-dodecane and a variety of reactors and flames, including autoignition, PSR, premixed flame propagation, and extinction of premixed and non-premixed counterflow flames. The validity of the assumption of fast fuel cracking at high temperature conditions is subsequently investigated with 2-D DNS of a lean turbulent premixed flame for $n$ butane/air using a reduced model derived from the detailed USC-Mech II.

\section{Performance of a reduced model for $\boldsymbol{n}$-dodecane with lumped fuel cracking steps}

\subsection{A brief review of the reduced model}

An approach to lump the fuel cracking reactions has been demonstrated in $[4,8]$. This approach assumes that the intermediates of the fuel cracking are all in quasi-steady state. It reduces the chemical complexity of the reaction processes and the model size in an efficient 
manner. For $n$-dodecane, the resulting lumped model contains only three species, namely, $n$ dodecane, 1-pentene and 1-hexene and approximately one and a half dozen reactions. The rate coefficients of the lumped reaction model are based on JetSurF 1.0 [17]. The lumped pyrolysis model was combined with USC-Mech II [7] to obtain a complete model of 123 species and 977 reactions, referred to as JetSurF 1.0-1, which has been validated against the detailed model and experiments over a wide range of conditions [8]. Subsequently, this lumped-detailed reaction model was reduced to 24 species and employed in a study of spray combustion of $n$-dodecane in a turbulent counterflow flame [15].

The three steps taken in the above model reduction are described here. The DRG-based methods, including DRG and DRGASA, were employed to remove unimportant species and reactions first from a range of combustion responses over the pressure range of 1 to 10 atm, initial temperatures from 1000 to $1600 \mathrm{~K}$ for auto-ignition, inlet temperature of $300 \mathrm{~K}$ for PSRs, and equivalence ratios from 0.5 to 1.5 . The $\mathrm{H}$ atom was selected as the starting species in the graph searching in DRG and the obtained skeletal model consists of 47 species and 359 reactions. After skeletal reduction with DRG, the model was further reduced with DRGASA to obtain a smaller model. The worst case error in target parameters induced by removing a single species was first tested and then sorted in ascending order. The species were then eliminated one by one until the worst case error in the target parameters reaches the given error tolerance. In DRGASA, auto-ignition delay with initial temperature from 1000 to $1600 \mathrm{~K}$ and extinction residence time of PSRs with inlet temperature of $300 \mathrm{~K}$ over the pressure range of 1 to 10 atm and equivalence ratio from 0.5 to 1.5 , were selected as the target responses with an error tolerance of $20 \%$. The final skeletal model is comprised of 193 reactions and 31 species: $\mathrm{N}_{2}, \mathrm{H}, \mathrm{O}, \mathrm{OH}, \mathrm{HO}_{2}, \mathrm{H}_{2}, \mathrm{H}_{2} \mathrm{O}$, $\mathrm{H}_{2} \mathrm{O}_{2}, \mathrm{O}_{2}, \mathrm{CH}_{2}, \mathrm{CH}_{2}^{*}, \mathrm{CH}_{3}, \mathrm{CH}_{4}, \mathrm{HCO}, \mathrm{CH}_{2} \mathrm{O}, \mathrm{CH}_{3} \mathrm{O}, \mathrm{CO}, \mathrm{CO}_{2}, \mathrm{C}_{2} \mathrm{H}_{2}, \mathrm{C}_{2} \mathrm{H}_{3}, \mathrm{C}_{2} \mathrm{H}_{4}, \mathrm{C}_{2} \mathrm{H}_{5}, \mathrm{C}_{2} \mathrm{H}_{6}$, 
$\mathrm{CH}_{2} \mathrm{CHO}, \mathrm{aC}_{3} \mathrm{H}_{5}$ (allyl), $\mathrm{C}_{3} \mathrm{H}_{6}, n \mathrm{C}_{3} \mathrm{H}_{7}, \mathrm{C}_{2} \mathrm{H}_{3} \mathrm{CHO}, \mathrm{C}_{4} \mathrm{H}_{8}-1$ (1-butene), $n \mathrm{C}_{12} \mathrm{H}_{26}$ (n-dodecane), and $\mathrm{C}_{6} \mathrm{H}_{12}$ (1-hexene). Reactions of any eliminated species were also removed. The skeletal submodel for fuel pyrolysis is provided in Table 1. In the last step, this skeletal model was further reduced with the LQSSA method [14]. Seven global QSS species, namely $\mathrm{CH}_{2}, \mathrm{CH}_{2} *, \mathrm{HCO}$, $\mathrm{CH}_{3} \mathrm{O}, \mathrm{C}_{2} \mathrm{H}_{3}, \mathrm{C}_{2} \mathrm{H}_{5}$, and $n \mathrm{C}_{3} \mathrm{H}_{7}$, were identified by excluding all species with nontrivial projection to the slow chemical subspace, thus resulting in a 24-species model. The QSS species are eliminated from the transport equations and can be solved with a set of internal algebraic equations. The QSSA equations are evaluated analytically using a graph-based method [14] to ensure high accuracy and robustness.

\subsection{Extended model validation}

Validation of the reduced model is rather limited in Ref. [15] and is extended in the present study, particularly regarding the effects of fuel cracking. The reduced model is first compared with the detailed JetSurF 1.0 and the lumped-detailed model, in which the elementary fuel cracking reactions of JetSurF 1.0 are replaced by lumped semi-global steps, for ignition delay and PSR extinction over a wide range of pressures, temperatures and equivalence ratios. Figure 1 shows excellent agreement of the three models despite some minor discrepancies between the detailed and lumped-detailed models.

The normalized total mass fraction of the species with four or more carbon atoms, denoted by $\mathrm{C}_{4+}$, are plotted in Fig. 2 as a function of temperature in auto-ignition and PSRs for different equivalence ratios and pressures. It is noted that, the PSR profiles in Fig. $2 \mathrm{c}$ and $2 \mathrm{~d}$ are plotted against temperature, which are corresponding to different residence time along the $S$ curve. It is seen that the total mass fraction of $\mathrm{C}_{4+}$, that is the molecules with four or more carbon 
atoms, decreases rapidly as temperature increases, and the fuel cracking is essentially complete by $1500 \mathrm{~K}$ in both the no-mixing (auto-ignition) and fully mixed (PSR) limits. In the context of flames and as will be discussed later, laminar premixed flames or flamelets involve some back mixing due to molecular diffusion. The fact that the fuel cracking process is mostly complete before $1500 \mathrm{~K}$ suggests that (a) fuel cracking always occurs in the preheat zone and (b) the fragments that enters the flame zone are primarily $\mathrm{C}_{\leq 4}$ species.

Figure 3 compares the laminar premixed flame speed calculated with the reduced, detailed and lumped-detailed models. The reduced model under-predicts the flame speed slightly. In the worst case, the discrepancy between the detailed and lumped-detailed, or lumpeddetailed and reduced, models is approximately $3 \mathrm{~cm} / \mathrm{s}$, occurring near the stoichiometric condition.

Figure 4 compares simulation results, calculated using the detailed, lumped-detailed and reduced models, and experimental data for auto-ignition delay and laminar flame speed. Figure 4(a) shows the calculated ignition delays of $n$-dodecane/air mixture at $p=20$ atm and $\phi=0.5$ compared with experimental data in Ref. [18]. Figure 4(b) compares calculated laminar flame speed and experimental data $[19,20]$ for $n$-dodecane/air as function of equivalence ratio at atmospheric pressure and freestream temperature of $403 \mathrm{~K}$. It is seen that, compared with detailed and lumped-detailed models, the reduced model under-predicts the flame speed with a worst case error of approximately $5 \mathrm{~cm} / \mathrm{s}$ near the stoichiometric condition.

To further investigate the validity of the model reduction approaches, the flame response to flow strain was tested in both non-premixed and premixed one-dimensional counterflow flames, comparing predictions made by three models. For non-premixed flames, the fuel jet is comprised of $50 \%$ (mol) $n$-dodecane in $\mathrm{N}_{2}$, and the oxidizer jet is air, both of which are at $300 \mathrm{~K}$ 
and $1 \mathrm{~atm}$. Figure $4 \mathrm{a}$ shows the maximum temperature, $T_{\max }$, computed for the non-premixed counterflow flames as a function of the strain rate $a_{2}$, defined in Ref. [21] as

$$
a_{2}=\frac{2\left|V_{2}\right|}{L}\left(1+\frac{\left|V_{1}\right| \sqrt{\rho_{1}}}{\left|V_{2}\right| \sqrt{\rho_{2}}}\right)
$$

where the subscripts 1 and 2 denote the fuel and oxidizer boundaries, respectively, $V$ is the axial component of the inlet velocity, $\rho$ is density, and $L$ is the burner separation distance. It is seen in Fig. 5 that the lumped model agrees well with the detailed model over the entire $T_{\max }-\mathrm{vs} .-1 / a$ curves, including the turning point, which corresponds to the extinction state of the flame. In the worst case, the 24 -species reduced model gives an error of $\sim 20 \%$ in the extinction strain rate. Figure $5 b$ further shows the normalized total mass fraction of $\mathrm{C}_{4+}$ species and those of $\mathrm{CH}_{4}, \mathrm{C}_{2} \mathrm{H}_{4}$ and $\mathrm{C}_{3} \mathrm{H}_{6}$. The three profiles shown in Fig. $5 \mathrm{~b}$ are calculated with rather different strain rates that span from strongly burning to near-extinction conditions. The fuel cracking behaviors are quite similar for all three strain rates and they are also similar to those computed for auto-ignition and PSR as shown in Fig. 2. Specifically, the $\mathrm{C}_{4+}$ species primarily vanish by about $1500 \mathrm{~K}$, indicating that the fuel cracking process is completed in the preheat zone before the main flame zone.

In the premixed counterflow flames studied, the twin jets are comprised of an $n$ dodecane/air mixture with an equivalence ratio of 0.7 at a temperature of $300 \mathrm{~K}$ and atmospheric pressure. Figure 6 shows the variation of the maximum temperature as a function of strain rate. Again, predictions using both the lumped-detailed and 24-species reduced models are close to that of the detailed model, including those near the extinction state. The largest discrepancies are observed at low strain rates due to the high sensitivity of flame temperature to the location of the flames and consequently the heat loss rate to the burner inlets. The normalized mass fraction of 
species $\mathrm{C}_{4+}$ and that of the primary fuel cracking products including $\mathrm{CH}_{4}, \mathrm{C}_{2} \mathrm{H}_{4}$ and $\mathrm{C}_{3} \mathrm{H}_{6}$ are shown in Fig. 6b as a function of temperature for three strain rates. Comparison of the premixed and non-premixed results shows similar features. In all cases, fuel cracking is complete before $1500 \mathrm{~K}$. Overall, the lumping approach is valid in predicting combustion responses of $n$ dodecane under near-extinction conditions.

Lastly, we note that the $\mathrm{C}_{0}-\mathrm{C}_{3}$ core of the current 24-species reduced model differ from the 22-species reduced model of ethylene combustion [22] by only three species, namely HCCO, $\mathrm{CH}_{2} \mathrm{CO}$ and $\mathrm{CH}_{3} \mathrm{CHO}$ that are replaced by $\mathrm{CH}_{2} \mathrm{CHO}$ and $\mathrm{C}_{2} \mathrm{H}_{3} \mathrm{CHO}$ in the current $n$-dodecane model. The implication is clear, in that it is reasonable to expect that the present model reduction approach is applicable to the high-T oxidation of most of the large hydrocarbons and their mixtures. The resulting reduced models will have sizes comparable to that of ethylene oxidation that involves only 20 to 30 species. With this model size large-scale turbulent flame simulations are well within our reach for practical liquid fuels.

\subsection{A bifurcation analysis on high-T ignition and extinction of PSR}

To further explain the insensitivity of high-T flame behaviors to the lumping of fuel cracking reactions, a bifurcation analysis [23] is performed to systematically identify the controlling species and reactions governing the high-T ignition and extinction of steady-state PSRs. Importantly, the impact of fuel cracking on ignition and extinction is examined using the same analysis for the first time. 
As a brief review of the bifurcation analysis, governing equations of a spatially discretized chemically reacting system can be expressed as

$$
\frac{D \mathbf{y}}{D t}=\mathbf{g}(\mathbf{y})=\boldsymbol{\omega}(\mathbf{y})+\mathbf{s}(\mathbf{y})
$$

where $\mathbf{y}$ is the vector of dependent variables, $\boldsymbol{\omega}$ is the chemical source term, and $\mathbf{s}$ represents the transport terms. For PSRs, $\mathbf{y}$ consists of the species mass fractions and temperature, and the source terms can be expressed as:

$$
\begin{gathered}
\omega_{i}(\mathbf{y})=\frac{\dot{m}_{i}}{\rho}, i=1,2, \ldots, \mathrm{K}, \omega_{K+1}(\mathbf{y})=-\frac{\sum_{i=1, K} \dot{m}_{i} h_{i}}{\rho c_{p}}, \\
s_{i}(\mathbf{y})=\frac{Y_{i}^{0}-Y_{i}}{\tau}, i=1,2, \ldots, \mathrm{K}, s_{K+1}(\mathbf{y})=\frac{\sum_{i=1, K} Y_{i}^{0}\left(h_{i}^{0}-h_{i}\right)}{c_{p} \tau}, \tau=\frac{\rho V}{\dot{M}_{i n}} .
\end{gathered}
$$

In the above equations, the subscript $i$ indicates the $i^{\text {th }}$ species, and the superscript 0 denotes the inlet condition. $Y$ is mass fraction, $K$ is the number of species considered, $\dot{m}_{i}$ is the mass production rate, $h_{i}$ is the specific enthalpy, and $c_{p}$ is the mixture specific heat. The residence time $\tau$ (the mixing time) is determined by the mass density $\rho$, the reactor volume $V$ and the inlet mass flow rate $\dot{M}_{\text {in }}$.

The bifurcation analysis is based on the Jacobian of the governing equations in Eq. (1)

$$
\mathbf{J}_{\mathbf{g}}=\partial \mathbf{g} / \partial \mathbf{y}=\mathbf{J}_{\boldsymbol{\omega}}+\mathbf{J}_{\mathbf{s}}, \quad \mathbf{J}_{\boldsymbol{\omega}}=\partial \boldsymbol{\omega} / \partial \mathbf{y}, \quad \mathbf{J}_{\mathbf{s}}=\partial \mathbf{s} / \partial \mathbf{y}
$$

where the full Jacobian $\mathbf{J}_{\mathbf{g}}$ may be decomposed into the chemical Jacobian, $\mathbf{J}_{\boldsymbol{\omega}}$, and the mixing Jacobian, $\mathbf{J}_{\mathbf{s}}$. The full Jacobian $\mathbf{J}_{\mathbf{g}}$ at the ignition and extinction states, which are bifurcation points of the $S$-curve, features $\operatorname{Re}\left(\lambda^{*}\right)=0$, where $\lambda^{*}$ is the complex eigenvalue of $\mathbf{J}_{\mathbf{g}}$ with the largest (most positive) real part [24]. To identify the role of a reaction in ignition and extinction 
of PSR, the Jacobian $\mathbf{J}_{\mathbf{g}}$ and its eigenvalue $\lambda^{*}$ can be decomposed into the contribution from each reaction:

$$
\begin{aligned}
& \mathbf{J}_{\mathbf{g}}=\mathbf{J}_{\boldsymbol{\omega}}+\mathbf{J}_{\mathbf{s}}=\sum_{r=1}^{I+1} \mathbf{J}_{r}, \mathbf{J}_{\boldsymbol{\omega}}=\sum_{r=1}^{I} \mathbf{J}_{r}, \mathbf{J}_{\mathbf{s}}=\mathbf{J}_{I+1}, \\
& \operatorname{Re}\left(\lambda^{*}\right)=\sum_{r=1}^{I+1} \operatorname{Re}\left(\lambda_{r}\right)=0, \lambda_{r}=\mathbf{b}^{*} \mathbf{J}_{r} \mathbf{a}^{*}
\end{aligned}
$$

where $I$ is the number of reactions. The subscript $r$ denotes the $r^{\text {th }}$ reaction for $r \leq I$. The mixing term is given by $r=I+1 . \mathbf{b}^{*}$ and $\mathbf{a}^{*}$ are the left and right eigenvectors, respectively, associated with $\lambda^{*}$. Equation $3 b$ shows that the bifurcation point where $\operatorname{Re}\left(\lambda^{*}\right)=0$ is resulting from the competition between the reaction and mixing. A bifurcation index (BI) can then be defined as

$$
\mathrm{BI}^{r}=\frac{\operatorname{Re}\left(\lambda_{r}\right)}{\max _{r}\left(\left|\operatorname{Re}\left(\lambda_{r}\right)\right|\right)} .
$$

The BI values range from -1 to 1 and indicate the contribution of each reaction to the zero-crossing of $\operatorname{Re}\left(\lambda^{*}\right)$. That is, the $r^{\text {th }}$ reaction is unimportant for the bifurcation if $\left|\mathrm{BI}^{r}\right| \ll 1$. Analytical derivatives are needed to evaluate the Jacobian to ensure adequate numerical precision $[23,24]$.

The PSR $S$-curve responses to $n$-dodecane, toluene and their binary mixtures, calculated with the detailed JetSurF 2.0 [25], are shown in Fig. 7. Toluene is considered here to test the effect of less reactive components in practical fuels, such as the aromatics in jet fuels. It is seen that an equal molar blending of the two fuels of drastically different reactivities yields ignition and extinction state values that are practically the same as those of pure $n$-dodecane. In contrast, pure toluene produces the $S$-curve drastically different from those of the fuel blends. To understand these observations, we applied bifurcation analysis of the extinction and ignition 
turning points on the four $S$-curves. Figure 8 shows the ranked bifurcation indices. It is seen that the extinction states are controlled by a similar set of reactions with nearly identical BI rankings, with or without toluene blending, as shown in Fig. 8a. They control radical branching and termination (e.g., $\mathrm{H}+\mathrm{O}_{2} \rightarrow \mathrm{O}+\mathrm{OH}$ and $\left.\mathrm{H}+\mathrm{OH}+\mathrm{M} \rightarrow \mathrm{H}_{2} \mathrm{O}+\mathrm{M}\right)$ or heat release $(\mathrm{CO}+\mathrm{OH} \rightarrow$ $\left.\mathrm{CO}_{2}+\mathrm{H}\right)$. The extinction state is unaffected by the fuel cracking process and none of the reactions reminiscent of the initial reactions of the fuel molecules appears in the ranked list. For the $S$-curve ignition state, the controlling reactions are typical of those that impact radical buildup through $\mathrm{OH}$ and $\mathrm{HO}_{2}$ and the oxidation of the fragments of fuel dissociation (ethylene, allyl, methyl and benzyl) by these same radicals. It is interesting to observe that with $50 \%$ toluene blending the benzyl radical scavenges the $\mathrm{HO}_{2}$ radical through the back reaction of $\mathrm{C}_{6} \mathrm{H}_{5} \mathrm{CH}_{3}+\mathrm{O}_{2} \rightarrow \mathrm{C}_{6} \mathrm{H}_{5} \mathrm{CH}_{2}+\mathrm{HO}_{2}$ which competes with the radical production reaction $\mathrm{C}_{6} \mathrm{H}_{5} \mathrm{CH}_{2}+\mathrm{HO}_{2}=\mathrm{C}_{6} \mathrm{H}_{5} \mathrm{CHO}+\mathrm{H}+\mathrm{OH}$. It is this competition that influences the ignition state when toluene is blended into $n$-dodecane. Again, the destruction of $n$-dodecane is not a rate limiting process for ignition even at $1000 \mathrm{~K}$. Consequently, reactions that are responsible for $n$ dodecane destruction do not appear at all in the ranked BI list shown in Fig. 8b.

The above results show that all of the rate limiting steps that control ignition and extinction are those involving small molecules. In such cases, the fast fuel-cracking reactions can be lumped by assuming that the intermediate species formed during the fuel cracking process are in quasi-steady state [4] even in the perfectly stirred limit. This feature of high-T fuel cracking can therefore be utilized to drastically reduce the chemical complexity in our approach, thus enabling the prediction of high-T oxidation of hydrocarbons quantitatively.

\section{Fuel cracking in DNS of a turbulence premixed flame}


To further investigate the fuel cracking effects in a turbulent environment, 2-D DNS is performed for a '2D-turbulent' premixed flame of $n$-butane/air. $n$-Butane is selected because it is the smallest $n$-alkane that features similar fuel cracking behavior exhibited in large $n$-alkanes, while the model size is suitable for DNS. A 25 -species reduced model for $n$-butane/air is developed from the 111-species detailed USC-Mech II using a similar procedure for the reduced $n$-dodecane model. Specifically, the detailed model was first reduced to a 36-species skeletal model using DRG and DRGASA. The skeletal model was further reduced to a 25-species reduced model with the LQSSA method. The reduction was performed for fuel lean conditions spanning an equivalence ratio range, $\phi=0.6-0.9$, pressures of 1-5 atm, initial temperatures of 1000 to $1600 \mathrm{~K}$ for auto-ignition, and an inlet temperature of 300K for PSR. In DRGASA, autoignition delay and extinction residence time of PSRs were selected as the target responses with an error tolerance of $20 \%$. Validations of the reduced model against the skeletal and detailed models are shown in Fig. 9, including ignition delay, PSR extinction, and the laminar flame speed.

The 25-species reduced model is then applied in DNS of a 2D turbulent premixed flame of $n$-butane/air using Sandia's DNS code, S3D [26], which solves the compressible NavierStokes, total energy and species conservation equations using a high order, low-dissipative finite difference scheme. A fourth-order explicit Runge-Kutta scheme [27] is used for time integration with chemical stiffness removed on-the-fly [28]. An eighth-order central differencing scheme is applied for spatial discretization, and a tenth-order filter is employed to remove high-frequency waves in the spatial profiles [29]. The CHEMKIN subroutines are employed to evaluate reaction rates, thermodynamic properties and mixture-averaged transport $[30,31]$. The computational domain is $10 \mathrm{~mm}(x)$ by $15 \mathrm{~mm}(y)$ discretized with a uniform grid size of $5 \mu \mathrm{m}$. Periodic 
boundary conditions are applied in the $x$-direction and non-reflecting outflow boundary conditions are applied in the $y$-direction. The flame is propagating into fresh mixtures of an equivalence ratio $\phi=0.6$ at a temperature of $500 \mathrm{~K}$ and pressure of 5 atm. The flow field is initialized with a 1-D premixed flame solution with a laminar flame speed of $29.9 \mathrm{~cm} / \mathrm{s}$ and thermal flame thickness of $0.14 \mathrm{~mm}$. The initial flame configuration is shown in Fig. 10a. A spectrum of isotropic turbulence is imposed on the initial flow field with an integral length of $l=$ $2.1 \mathrm{~mm}$ and velocity fluctuation $u^{\prime}=20.9 \mathrm{~m} / \mathrm{s}$, resulting in a turbulence Reynolds number of $R e_{t}$ $=1000$ and a Karlovitz number of $K a=250$ as denoted in the Borghi diagram in Fig. 10b.

Although the DNS was performed in two dimensions for computational efficiency, the flame structure obtained is consistent in the energy-containing scales with three-dimensional turbulent simulations. The fine-scale mixing is likely to differ between the $2 \mathrm{D}$ and $3 \mathrm{D}$ turbulence; however, heat release and viscous dissipation effects will dampen the intensity of eddies, particularly small eddies in the dissipative end of the turbulent kinetic energy spectrum as demonstrated from earlier flame-vortex simulations [32] such that wrinkling of the flame will be achieved predominantly by energy-containing eddy scales. The flame structure at different time instances are shown in Fig. 11, with the left panels showing the isocontour of fuel mass fraction. The white isolines indicate the flame zone location identified using chemical explosive mode analysis (CEMA) [33, 34], which is a systematic approach to detect ignition, extinction and premixed flame fronts locations in complex flow fields. It is seen that the flame fronts are significantly disturbed by the strong turbulence at the different time instances. However, a buffer is always present between the flame zone and the regimes with high concentration of fuel, indicating that the concentration of fuel molecules that enter into the flame zone is negligible even in the highly turbulent environment. A video showing the fully detailed time evolvement of 
the fuel mass fraction field is provided as supplementary material. The scatter plots of mass fractions of fuel and primary fuel cracking products, $\mathrm{C}_{2} \mathrm{H}_{4}$ and $\mathrm{C}_{3} \mathrm{H}_{6}$, in the right panels show that the fuel cracking behavior at the intense turbulence condition resembles that in 1-D laminar flames indicated by the solid lines, and the fuel cracking is essentially completed by approximately $1500 \mathrm{~K}$, before reaching the flame zone. Note that, $\mathrm{CH}_{4}$ is not present in the reduced $n$-butane model. This observation on fuel cracking is consistent with that obtained from the lower-dimensional 0- and 1-D systems.

\section{Concluding remarks}

The present study sheds further light on the approach of lumping fuel cracking as a means of achieving reaction model reduction. The primary focus of the analysis presented here addresses the model responses to high-T fuel oxidation in the limits of auto-ignition (no back mixing) and perfectly stirred reactors (complete back mixing), with extended investigation using

2-D DNS of a strongly turbulent premixed flame. The findings may be summarized as follows:

1) A 24-species reduced model for high-T oxidation of $n$-dodecane yields satisfactory results compared to the detailed model. Combined with other observations made in the present study, we expect that many problems in high-temperature combustion of large hydrocarbons and their mixtures can be adequately addressed with less than approximately 35 species, a level that is well within reach even for high-fidelity turbulent reacting simulations.

2) When toluene is blended with $n$-alkanes, the combustion responses gravitate towards those of $n$-alkanes, thus damping the impact of aromatics present in the fuel. 
3) Bifurcation analysis of the PSR extinction and ignition states yields results consistent with previous understanding, i.e. fuel cracking is fast even under PSR extinction and high-T ignition states that are all controlled by reactions of small species. For extinction, these are radical branching and termination, and the oxidation of $\mathrm{CO}$ to $\mathrm{CO}_{2}$. For ignition, the reactions are $\mathrm{CH}_{4}, \mathrm{C}_{2} \mathrm{H}_{4}$ and $\mathrm{C}_{3} \mathrm{H}_{6}$ oxidation along with those that impact $\mathrm{OH}$ and $\mathrm{HO}_{2}$ production.

4) All of the above observations support the approach of lumping fuel cracking into a few short steps as the means to reduce the chemical complexity of the model and to reduce the model size efficiently. Coupled with a detailed foundational fuel model of $\mathrm{H}_{2}, \mathrm{CO}$, and $\mathrm{C}_{\leq 4}$ species, the lumped approach is shown to work well for predicting key combustion responses, including auto-ignition, PSR extinction and ignition states, laminar flame speed and laminar premixed and non-premixed flame extinction.

5) 2-D DNS of a turbulent premixed flame for $n$-butane/air shows that an insignificant amount of fuel molecules enters the flame zone, even at the strongly turbulent environment, and thus the flame zone behavior is primarily controlled by oxidation of the fuel cracking products.

6) The above findings all suggest that real fuel combustion chemistry research would benefit by focusing efforts on the chemistry of small hydrocarbon species, as this is the key component in ensuring predictive accuracy.

Despite the comprehensiveness and accuracy observed in the present study for the present modeling approach, it is important to note again the limitation of applicability. First, the present hybrid models should only be applied to high-temperature combustion since low-temperature pathways, e.g., those responsible for the negative temperature coefficient (NTC) behaviors, are not considered. The extensive validation in the present study shows that the assumptions behind 
the hybrid modeling are valid for temperatures above approximately $1000 \mathrm{~K}$. In the NTC regime, the fuel cracking reactions may not be fast compared with the subsequent oxidation processes. Since the temperature boundary where low-T chemistry becomes important slightly increases with pressure. The hybrid models should be applied above a higher temperature boundary at elevated pressures, say approximately $1100 \mathrm{~K}$ for auto-ignition at $30 \mathrm{~atm}$. Furthermore, since the formation of polycyclic aromatic hydrocarbons (PAHs) are not considered, the hybrid models in the present form are not readily applicable for PAH-based soot modeling, and further study is necessary for NTC chemistry and PAH formation. In principle, NO formation nevertheless can be predicted using the hybrid models, since the intermediates to NO formation are included in the $\mathrm{C}_{0}-\mathrm{C}_{4}$ core of the lumped-detailed model. While $\mathrm{CH}$ is not included in the reduced model, it can be readily added if prompt NO is of interest. Lastly, although the hybrid models are shown to be robust over a wide range of conditions, including the 2-D 'turbulent' DNS of a $n$-butane/air premixed flame with Karlovitz number of 250, their performance remain unexplored in real engine environments.

\section{Acknowledgement}

This work was supported by the Air Force Office of Scientific Research under Grant FA955013-1-0057 and FA9550-11-1-0217, and by the Division of Chemical Sciences, Geosciences and Biosciences, Office of Basic Energy Sciences of the US Department of Energy. Sandia is a multiprogram laboratory operated by Sandia Corporation, a Lockheed Martin Company, for the United States Department of Energy under contract DE-AC04-94AL85000. 


\section{References}

[1] C. K. Westbrook, W. J. Pitz, O. Herbinet, H. J. Curran, E. J. Silke, Combust. Flame 156 (1) (2009) 181-199.

[2] S. M. Sarathy, C. K. Westbrook, M. Mehl, W. J. Pitz, C. Togbe, P. Dagaut, H. Wang, M. A. Oehlschlaeger, U. Niemann, K. Seshadri, P. S. Veloo, C. Ji, F. N. Egolfopoulos, T. Lu, Combust. Flame 158 (12) (2011) 2338-2357.

[3] S. M. Sarathy, C. Yeung, C. K. Westbrook, W. J. Pitz, M. Mehl, M. J. Thomson, Combust. Flame 158 (7) (2011) 1277-1287.

[4] X. You, F. N. Egolfopoulos, H. Wang, Proc. Combust. Inst. 32 (1) (2009) 403-410.

[5] D. F. Davidson, S. C. Ranganath, K. Y. Lam, M. Liaw, Z. Hong, R. K. H, J. Propul. Power 26 (2) (2010) 280-287.

[6] T. Malewicki, K. Brezinsky, Proc. Combust. Inst. 34 (1) (2013) 361-368.

[7] H. Wang, X. You, A. Joshi, S. Davis, A. Laskin, F. Egolfopoulos, C. Law USC Mech Version II. High-Temperature Combustion Reaction Model of H2/CO/C1-C4 Compounds. http://ignis.usc.edu/USC_Mech_II.htm

[8] E. D. B. Sirjean, D. A. Sheen, H. Wang, JetSurF 1.0-1: Simplified chemical kinetic models for high-temperature oxidation of $\mathrm{C} 1$ to $\mathrm{C} 12$ n-alkanes, in: 6th U.S. National Combustion Meeting, Ann Arbor, Michigan, 2009, Paper 23.F1.

[9] T. F. Lu, C. K. Law, Prog. Energy Combust. Sci. 35 (2) (2009) 192-215.

[10] T. F. Lu, C. K. Law, Proc. Combust. Inst. 30 (2005) 1333-1341.

[11] T. F. Lu, C. K. Law, Combustion and Flame 146 (3) (2006) 472-483.

[12] X. L. Zheng, T. F. Lu, C. K. Law, Proc. Combust. Inst. 31 (2007) 367-375. 
[13] R. Sankaran, E. R. Hawkes, J. H. Chen, T. F. Lu, C. K. Law, Proc. Combust. Inst. 31 (2007) 1291-1298.

[14] T. F. Lu, C. K. Law, J. Phys. Chem. A 110 (49) (2006) 13202-13208.

[15] A. Vié, B. Franzelli, Y. Gao, T. Lu, H. Wang, M. Ihme, Proc. Combust. Inst. 35 (2) (2015) $1675-1683$.

[16] C. K. Law, Combustion physics, Cambridge University Press, New York, 2006.

[17] B. Sirjean, E. Dames, D. A. Sheen, X. Q. You, C. Sung, A. T. Holley, F. N. Egolfopoulos, H. Wang, S. S. Vasu, D. F. Davidson, R. K. Hanson, H. Pitsch, C. T. Bowman, A. Kelley, C. K. Law, W. Tsang, N. P. Cernansky, D. L. Miller, A. Violi, R. P. Lindstedt A high-temperature chemical kinetic model of n-alkane oxidation, JetSurF 1.0, September 15, 2009. http://web.stanford.edu/group/haiwanglab/JetSurF/JetSurF1.0/index.html

[18] S. S. Vasu, D. F. Davidson, Z. Hong, V. Vasudevan, R. K. Hanson, Proc. Combust. Inst. 32 (1) (2009) 173-180.

[19] K. Kumar, C.-J. Sung, Combust. Flame 151 (1-2) (2007) 209-224.

[20] C. Ji, E. Dames, Y. L. Wang, H. Wang, F. N. Egolfopoulos, Combust. Flame 157 (2) (2010) 277-287.

[21] K. Seshadri, F. A. Williams, Int. J. Heat Mass Transfer 21 (2) (1978) 251-253.

[22] Z. Luo, C. S. Yoo, E. S. Richardson, J. H. Chen, C. K. Law, T. Lu, Combust. Flame 159 (1) (2011) 265-274.

[23] R. Shan, T. Lu, Combust. Flame 161 (7) (2014) 1716-1723.

[24] R. Shan, T. Lu, Combust. Flame 159 (6) (2012) 2069-2076.

[25] H. Wang, E. Dames, B. Sirjean, D. A. Sheen, R. Tangko, A. Violi, J. Y. W. Lai, F. N. Egolfopoulos, D. F. Davidson, R. K. Hanson, C. T. Bowman, C. K. Law, W. Tsang, N. P. 
Cernansky, D. L. Miller, R. P. Lindstedt A high-temperature chemical kinetic model of n-alkane (up to n-dodecane), cyclohexane, and methyl-, ethyl-, n-propyl and n-butyl-cyclohexane oxidation at high temperatures, JetSurF version 2.0, September 19, 2010. http://web.stanford.edu/group/haiwanglab/JetSurF/JetSurF2.0/index.html

[26] J. H. Chen, A. Choudhary, B. de Supinski, M. DeVries, E. R. Hawkes, S. Klasky, W. K. Liao, K. L. Ma, J. Mellor-Crummey, N. Podhorszki, R. Sankaran, S. S., C. S. Yoo, Comp. Sci. Disc. 2 (2009) 015001.

[27] C. A. Kennedy, M. H. Carpenter, Appl. Numer. Math. 14 (4) (1994) 397-433.

[28] T. F. Lu, C. K. Law, C. S. Yoo, J. H. Chen, Combust. Flame 156 (8) (2009) 1542-1551.

[29] C. A. Kennedy, M. H. Carpenter, R. M. Lewis, Appl. Numer. Math. 35 (3) (2000) 177-219.

[30] R. J. Kee, G. Dixon-Lewis, J. Warnatz, M. E. Coltrin, J. A. Miller, A Fortran Computer Code Package for the Evaluation of Gas-phase Multicomponent Transport Properties, Tech. Rep. SAND86-8246, Sandia National Laboratories, 1986.

[31] R. J. Kee, F. M. Rupley, E. Meeks, CHEMKIN-III: A Fortran Chemical Kinetic Package for the Anaylsis of Gas-phase Chemical and Plasma Knietics, Tech. Rep. SAND96-8216, Sandia National Laboratories, 1996

[32] T. Poinsot, D. Veynante, S. Candel, Symposium (International) on Combustion 23 (1) (1991) 613-619.

[33] T. F. Lu, C. S. Yoo, J. H. Chen, C. K. Law, J. Fluid Mech. 652 (1) (2010) 45-64.

[34] R. Shan, C. S. Yoo, J. H. Chen, T. Lu, Combust. Flame 159 (10) (2012) 3119-3127. 
Table 1. The skeletal fuel pyrolysis sub-model for $n$-dodecane

\begin{tabular}{|c|c|c|c|c|}
\hline No. & Reaction & $A$ & $n$ & $E_{a}$ \\
\hline 1 & $n-\mathrm{C}_{12} \mathrm{H}_{26}=>\mathrm{C}_{6} \mathrm{H}_{12}+\mathrm{C}_{2} \mathrm{H}_{4}+n-\mathrm{C}_{3} \mathrm{H}_{7}+\mathrm{CH}_{3}$ & $8.53 \times 10^{23}$ & -2.03 & 90034 \\
\hline 2 & $n-\mathrm{C}_{12} \mathrm{H}_{26}=>\mathrm{C}_{6} \mathrm{H}_{12}+2 n-\mathrm{C}_{3} \mathrm{H}_{7}$ & $5.64 \times 10^{26}$ & -2.68 & 88171 \\
\hline 3 & $n-\mathrm{C}_{12} \mathrm{H}_{26}=>\mathrm{C}_{4} \mathrm{H}_{8}-1+\mathrm{C}_{2} \mathrm{H}_{4}+2 n-\mathrm{C}_{3} \mathrm{H}_{7}$ & $7.88 \times 10^{25}$ & -2.65 & 88391 \\
\hline 4 & $n-\mathrm{C}_{12} \mathrm{H}_{26}=>2 \mathrm{C}_{3} \mathrm{H}_{6}+2 n-\mathrm{C}_{3} \mathrm{H}_{7}$ & $4.00 \times 10^{26}$ & -2.66 & 88392 \\
\hline 5 & $n-\mathrm{C}_{12} \mathrm{H}_{26}+\mathrm{H}=>\mathrm{C}_{6} \mathrm{H}_{12}+\mathrm{C}_{3} \mathrm{H}_{6}+n-\mathrm{C}_{3} \mathrm{H}_{7}+\mathrm{H}_{2}$ & $1.30 \times 10^{6}$ & 2.54 & 6756 \\
\hline 6 & $n-\mathrm{C}_{12} \mathrm{H}_{26}+\mathrm{H} \Rightarrow \mathrm{C}_{6} \mathrm{H}_{12}+\mathrm{C}_{3} \mathrm{H}_{6}+n-\mathrm{C}_{3} \mathrm{H}_{7}+\mathrm{H}_{2}$ & $5.20 \times 10^{6}$ & 2.40 & 4471 \\
\hline 7 & $n-\mathrm{C}_{12} \mathrm{H}_{26}+\mathrm{O} \Rightarrow \mathrm{C}_{6} \mathrm{H}_{12}+\mathrm{C}_{3} \mathrm{H}_{6}+n-\mathrm{C}_{3} \mathrm{H}_{7}+\mathrm{OH}$ & $2.50 \times 10^{6}$ & 2.40 & 5504 \\
\hline 8 & $n-\mathrm{C}_{12} \mathrm{H}_{26}+\mathrm{O} \Rightarrow \mathrm{C}_{6} \mathrm{H}_{12}+\mathrm{C}_{3} \mathrm{H}_{6}+n-\mathrm{C}_{3} \mathrm{H}_{7}+\mathrm{OH}$ & $4.60 \times 10^{5}$ & 2.60 & 1768 \\
\hline 9 & $n-\mathrm{C}_{12} \mathrm{H}_{26}+\mathrm{OH} \Rightarrow \mathrm{C}_{6} \mathrm{H}_{12}+\mathrm{C}_{3} \mathrm{H}_{6}+n-\mathrm{C}_{3} \mathrm{H}_{7}+\mathrm{H}_{2} \mathrm{O}$ & $1.40 \times 10^{7}$ & 1.80 & 974 \\
\hline 10 & $n-\mathrm{C}_{12} \mathrm{H}_{26}+\mathrm{OH} \Rightarrow \mathrm{C}_{6} \mathrm{H}_{12}+\mathrm{C}_{3} \mathrm{H}_{6}+n-\mathrm{C}_{3} \mathrm{H}_{7}+\mathrm{H}_{2} \mathrm{O}$ & $4.00 \times 10^{6}$ & 2.00 & -596 \\
\hline 11 & $n-\mathrm{C}_{12} \mathrm{H}_{26}+\mathrm{CH}_{3} \Rightarrow \mathrm{C}_{6} \mathrm{H}_{12}+\mathrm{C}_{3} \mathrm{H}_{6}+n-\mathrm{C}_{3} \mathrm{H}_{7}+\mathrm{CH}_{4}$ & $9.03 \times 10^{-1}$ & 3.65 & 7153 \\
\hline 12 & $n-\mathrm{C}_{12} \mathrm{H}_{26}+\mathrm{CH}_{3}=>\mathrm{C}_{6} \mathrm{H}_{12}+\mathrm{C}_{3} \mathrm{H}_{6}+n-\mathrm{C}_{3} \mathrm{H}_{7}+\mathrm{CH}_{4}$ & 6.00 & 3.46 & 5480 \\
\hline 13 & $n-\mathrm{C}_{12} \mathrm{H}_{26}+\mathrm{O}_{2} \Rightarrow \mathrm{C}_{6} \mathrm{H}_{12}+\mathrm{C}_{3} \mathrm{H}_{6}+n-\mathrm{C}_{3} \mathrm{H}_{7}+\mathrm{HO}_{2}$ & $4.00 \times 10^{13}$ & 0.00 & 50930 \\
\hline 14 & $n-\mathrm{C}_{12} \mathrm{H}_{26}+\mathrm{O}_{2}=>\mathrm{C}_{6} \mathrm{H}_{12}+\mathrm{C}_{3} \mathrm{H}_{6}+n-\mathrm{C}_{3} \mathrm{H}_{7}+\mathrm{HO}_{2}$ & $1.60 \times 10^{14}$ & 0.00 & 47590 \\
\hline 15 & $n-\mathrm{C}_{12} \mathrm{H}_{26}+\mathrm{HO}_{2}=>\mathrm{C}_{6} \mathrm{H}_{12}+\mathrm{C}_{3} \mathrm{H}_{6}+n-\mathrm{C}_{3} \mathrm{H}_{7}+\mathrm{H}_{2} \mathrm{O}_{2}$ & $4.76 \times 10^{4}$ & 2.55 & 16490 \\
\hline 16 & $n-\mathrm{C}_{12} \mathrm{H}_{26}+\mathrm{HO}_{2}=>\mathrm{C}_{6} \mathrm{H}_{12}+\mathrm{C}_{3} \mathrm{H}_{6}+n-\mathrm{C}_{3} \mathrm{H}_{7}+\mathrm{H}_{2} \mathrm{O}_{2}$ & $3.80 \times 10^{4}$ & 2.60 & 13910 \\
\hline
\end{tabular}

Rate coefficient expressed as $k=A T^{n} \exp \left(-E_{a} / R T\right)$. Units are mole, $\mathrm{cm}, \mathrm{s}$, cal, and $\mathrm{K}$. 


\section{Figure Captions}

Figure 1. Auto-ignition delays (left panels) and extinction temperature of PSR (right panels) for $n$-dodecane/air mixtures at equivalence ratios of $0.5,1.0$ and 1.5 and pressures of 1 and 10 atm, calculated with the detailed JetSurF 1.0 (solid lines), the lumped-detailed model (dashed lines) and the 24-species reduced model (symbols), respectively.

Figure 2. Normalized total mass fraction of $\mathrm{C}_{4}$ species and larger, denoted as $\mathrm{C}_{4+}$, as a function of temperature in auto-ignition and PSRs for $n$-dodecane/air mixtures at equivalence ratios of 0.5, 1.0 and 1.5, and pressures of 1 and 10 atm, calculated with the detailed JetSurF 1.0 (solid lines) and the 24-species reduced model (symbols).

Figure 3. Laminar flame speed as a function of equivalence ratio for $n$-dodecane/air mixtures at an initial temperature of $300 \mathrm{~K}$ and pressures of 1 and $10 \mathrm{~atm}$.

Figure 4. Comparison of predicted results (lines) and experimentally measurements (symbols) for $n$-dodecane/air: (a) ignition delay at $\phi=0.5, p=20 \mathrm{~atm}$, (b) laminar flame speed as function of equivalence ratio at atmospheric pressure and freestream temperature of $403 \mathrm{~K}$.

Figure 5. (a) Comparison of the maximum temperature $T_{\max }$ in counterflow non-premixed flames as a function of the strain rate, calculated with the detailed, lumped-detailed and 24species reduced models; (b) Normalized total mass fraction of $\mathrm{C}_{4+}$ species, and that of the primary fuel cracking products, including $\mathrm{CH}_{4}, \mathrm{C}_{2} \mathrm{H}_{4}$ and $\mathrm{C}_{3} \mathrm{H}_{6}$, at three different strain rates as predicted by the detailed model. The flames are at atmospheric pressure and an inlet temperature of $300 \mathrm{~K}$ with the fuel jet comprised of $50 \%$ (mol) $n$-dodecane in $\mathrm{N}_{2}$ and air at $300 \mathrm{~K}$ as the oxidizer jet.

Figure 6. (a) Comparison of maximum temperature $T_{\max }$ in counterflow premixed flames as a function of the strain rate, calculated with the detailed, lumped-detailed and 24-species reduced models; (b) Normalized total mass fraction of $\mathrm{C}_{4+}$ species, and that of the primary fuel cracking products, including $\mathrm{CH}_{4}, \mathrm{C}_{2} \mathrm{H}_{4}$ and $\mathrm{C}_{3} \mathrm{H}_{6}$, at three different strain rates as predicted by the detailed model. The flames are at atmospheric pressure and an inlet temperature of $300 \mathrm{~K}$ with the twin jets composed of an $n$-dodecane/air mixture at $\phi=0.7$.

Figure 7. $S$-curves in PSR for $n$-dodecane, toluene and their mixtures at pressure of 10 atm, $\phi=$ 0.7 and inlet temperature of $1000 \mathrm{~K}$, calculated with the detailed JetSurF 2.0.

Figure 8. Largest, ranked bifurcation index of reactions computed for extinction (a) and ignition (b) states on the PSR $S$-curves of Fig. 6, comparing pure $n$-dodecane with two binary mixtures of $n$-dodecane and toluene.

Figure 9. Ignition delays, PSR extinction and laminar flame speed for $n$-butane/air mixtures at equivalence ratios of $\phi=0.6-0.9$ and pressures of 1 and 5 atm, calculated with the detailed, skeletal and reduced models.

Figure 10. (a) Initial temperature isocontour for the 2-D DNS of $n$-butane/air, and (b) location of the DNS case on the Borghi diagram $\left(K a=250, R e_{t}=1000\right)$. 
Figure 11. Left panels: Isocontour of fuel mass fraction (red: fresh mixture, blue: hot products), and right panels: scatter plots of mass fractions of fuel and primary cracking products vs. temperature, for DNS of a turbulent premixed flame of $n$-butane/air at different time instances. The white isolines on the left panels show the flame zone identified using CEMA. The solid lines on the right panels are solutions from 1-D steady state premix flame with the same fresh mixture condition as that in the DNS. 


\section{Figures}
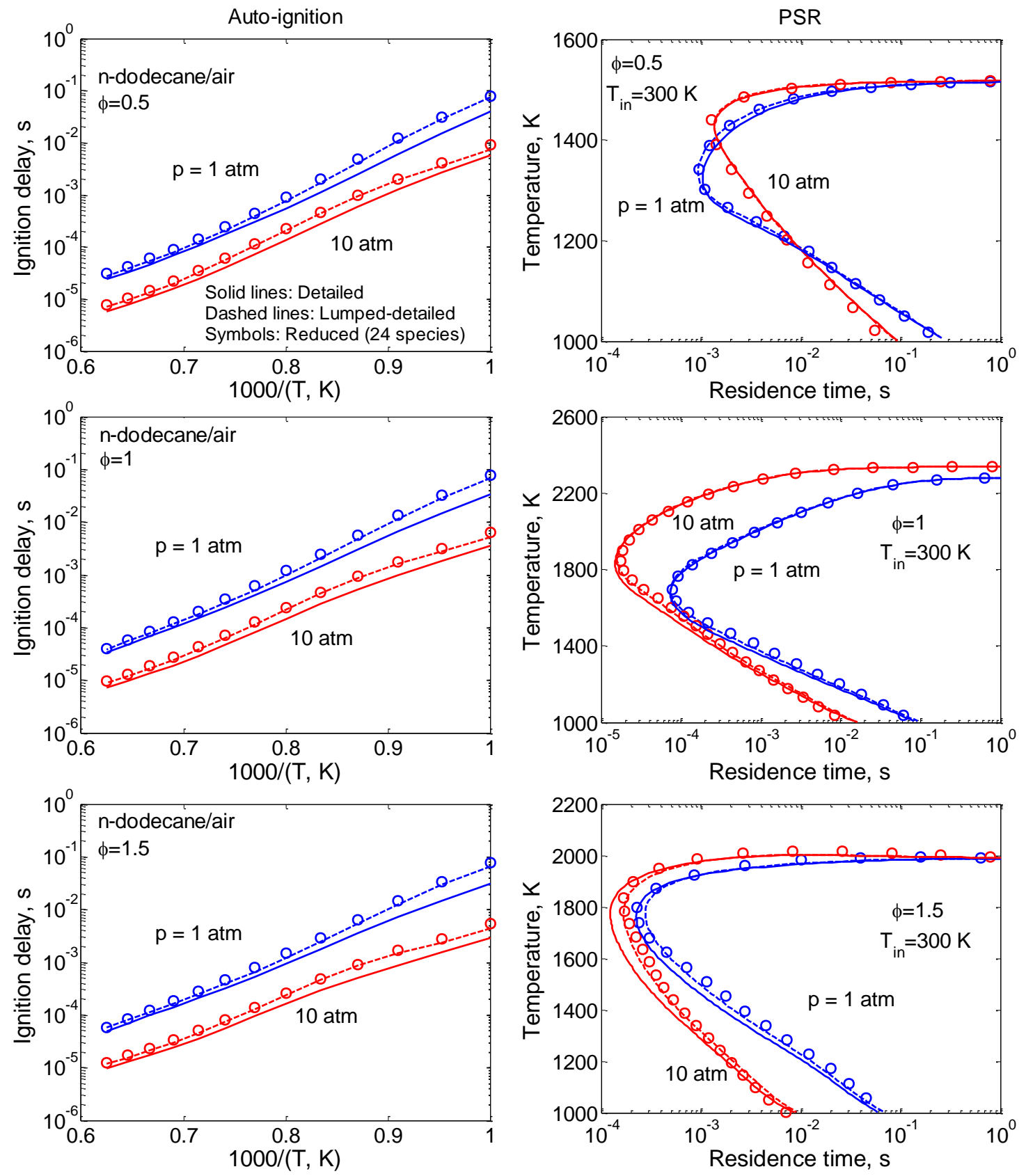

Figure 1. Auto-ignition delays (left panels) and extinction temperature of PSR (right panels) for $n$-dodecane/air mixtures at equivalence ratios of $0.5,1.0$ and 1.5 and pressures of 1 and 10 atm, calculated with the detailed JetSurF 1.0 (solid lines), the lumped-detailed model (dashed lines) and the 24-species reduced model (symbols), respectively. 

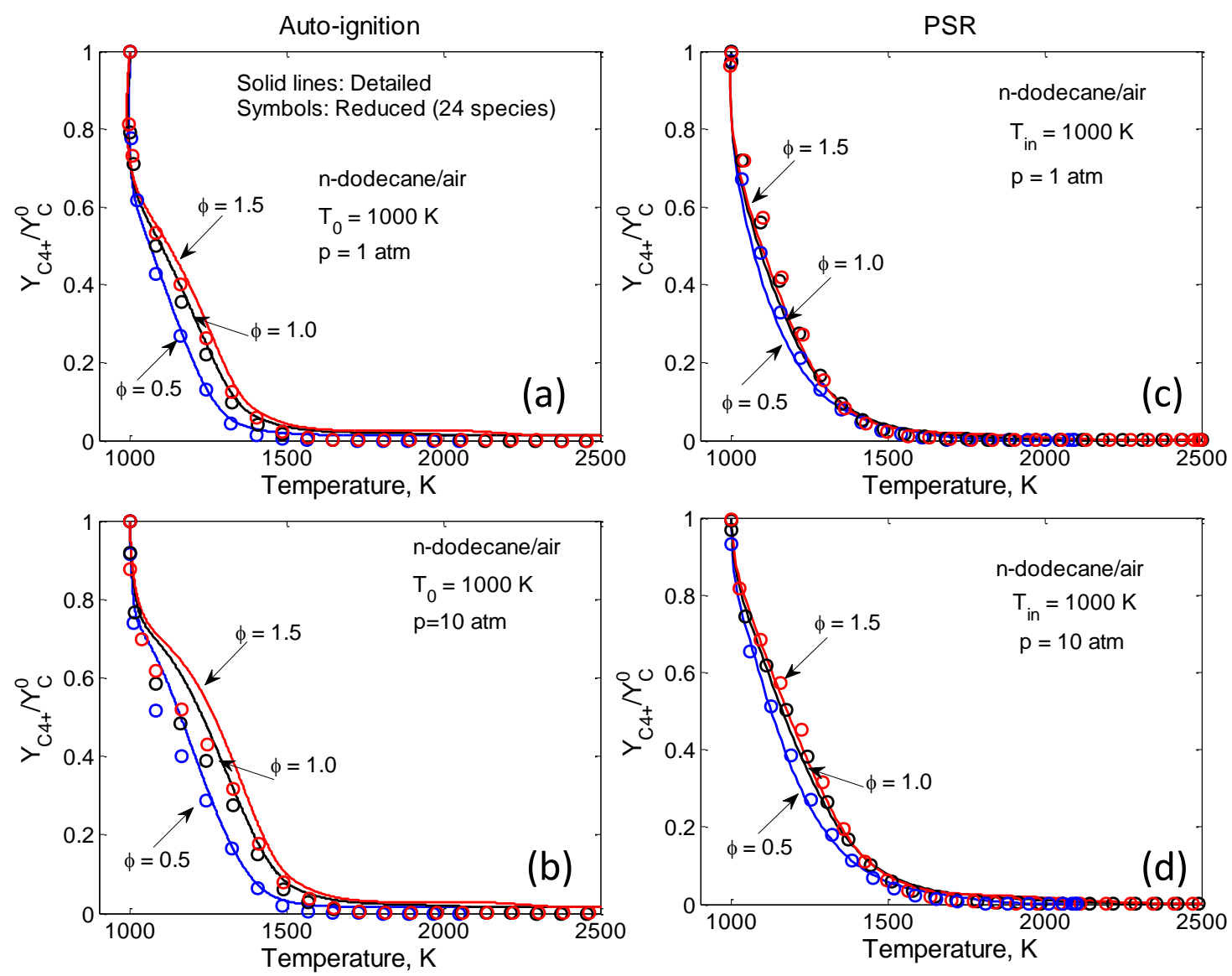

Figure 2. Normalized total mass fraction of $\mathrm{C}_{4}$ species and larger, denoted as $\mathrm{C}_{4+}$, as a function of temperature in auto-ignition and PSRs for $n$-dodecane/air mixtures at equivalence ratios of 0.5, 1.0 and 1.5, and pressures of 1 and 10 atm, calculated with the detailed JetSurF 1.0 (solid lines) and the 24-species reduced model (symbols). 


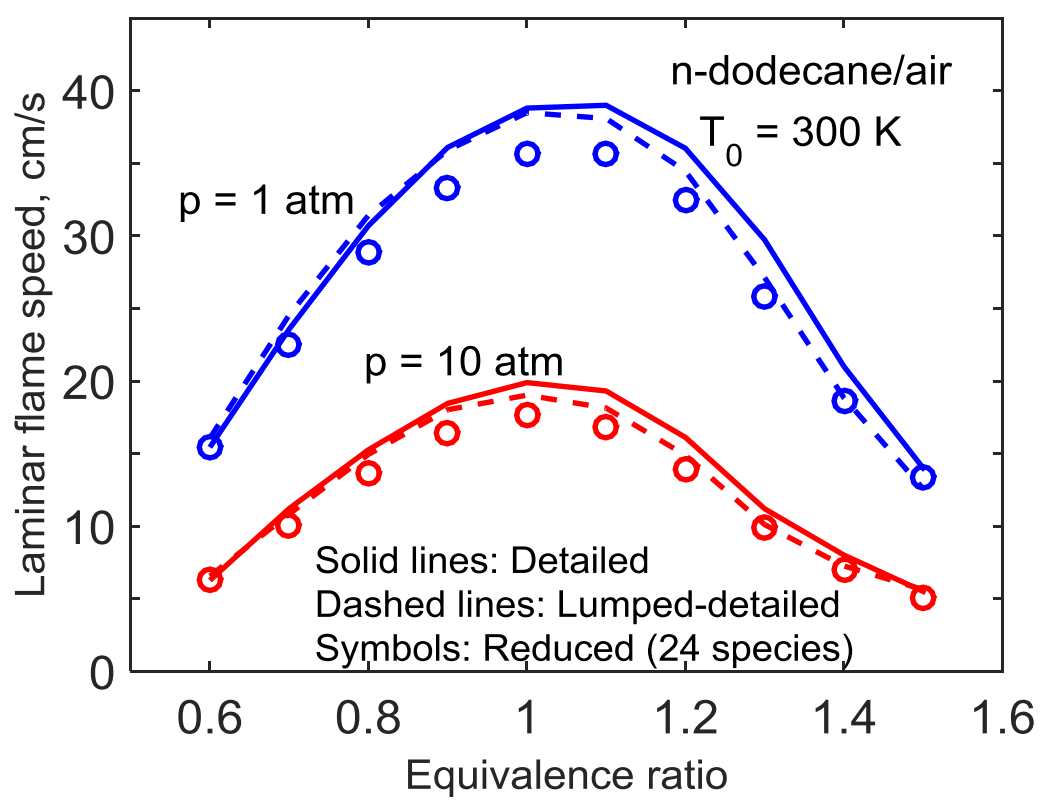

Figure 3. Laminar flame speed as a function of equivalence ratio for $n$-dodecane/air mixtures at an initial temperature of $300 \mathrm{~K}$ and pressures of 1 and $10 \mathrm{~atm}$. 

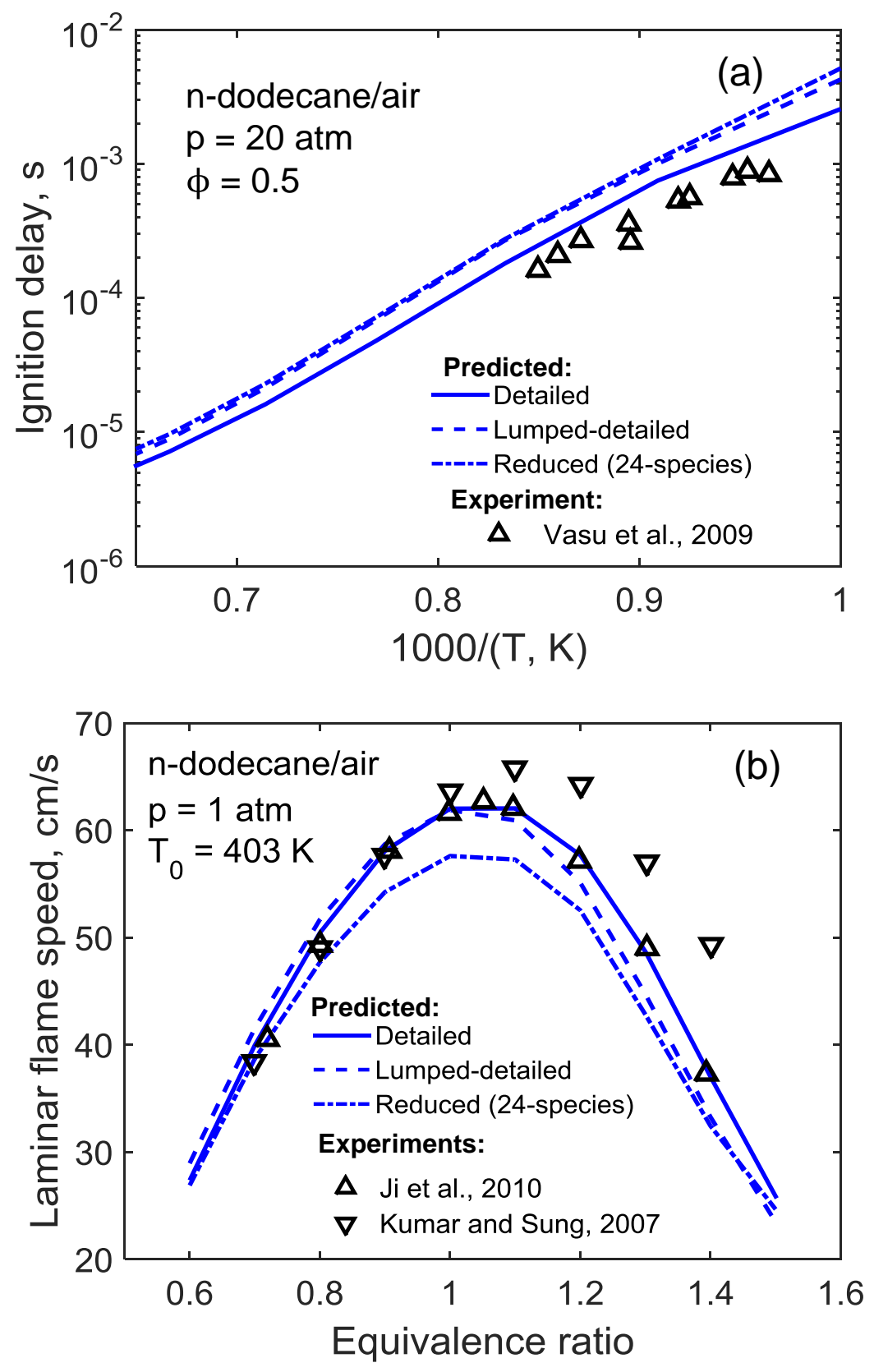

Figure 4. Comparison of predicted results (lines) and experimentally measurements (symbols) for $n$-dodecane/air: (a) ignition delay at $\phi=0.5, p=20 \mathrm{~atm}$, (b) laminar flame speed as function of equivalence ratio at atmospheric pressure and freestream temperature of $403 \mathrm{~K}$. 

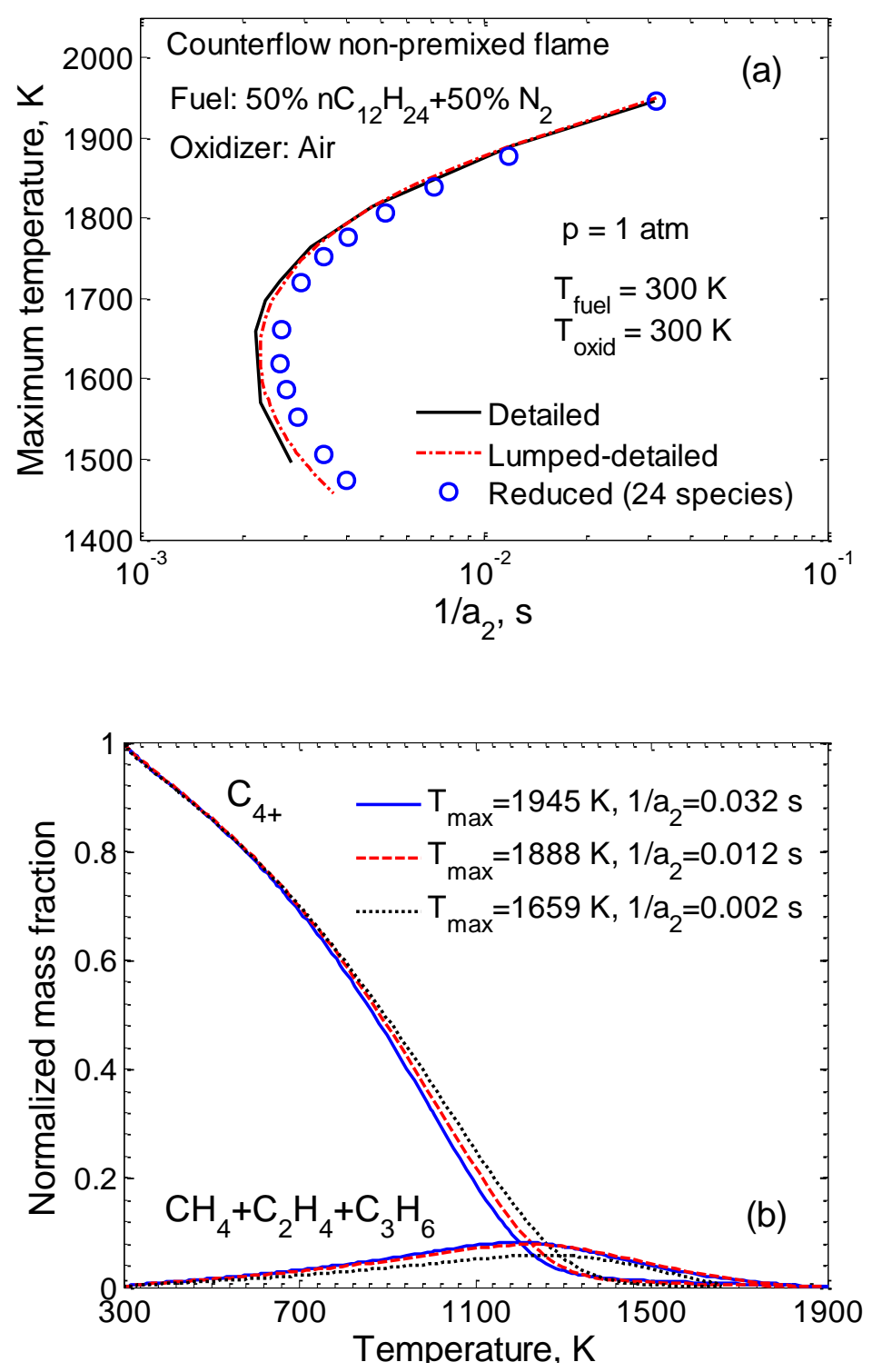

Figure 5. (a) Comparison of the maximum temperature $T_{\max }$ in counterflow non-premixed flames as a function of the strain rate, calculated with the detailed, lumped-detailed and 24species reduced models; (b) Normalized total mass fraction of $\mathrm{C}_{4+}$ species, and that of the primary fuel cracking products, including $\mathrm{CH}_{4}, \mathrm{C}_{2} \mathrm{H}_{4}$ and $\mathrm{C}_{3} \mathrm{H}_{6}$, at three different strain rates as predicted by the detailed model. The flames are at atmospheric pressure and an inlet temperature of $300 \mathrm{~K}$ with the fuel jet comprised of $50 \%$ (mol) $n$-dodecane in $\mathrm{N}_{2}$ and air at $300 \mathrm{~K}$ as the oxidizer jet. 

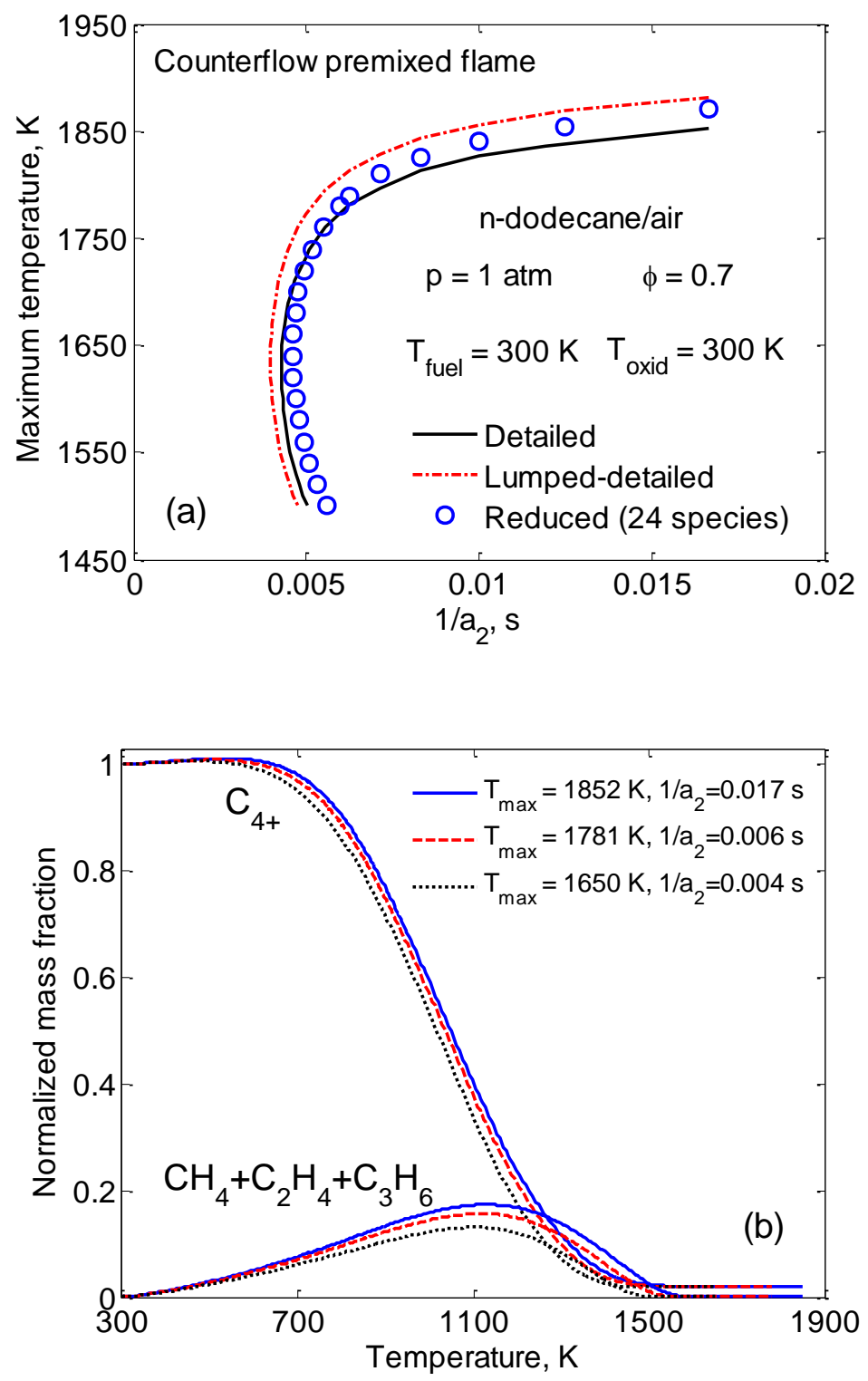

Figure 6. (a) Comparison of maximum temperature $T_{\max }$ in counterflow premixed flames as a function of the strain rate, calculated with the detailed, lumped-detailed and 24-species reduced models; (b) Normalized total mass fraction of $\mathrm{C}_{4+}$ species, and that of the primary fuel cracking products, including $\mathrm{CH}_{4}, \mathrm{C}_{2} \mathrm{H}_{4}$ and $\mathrm{C}_{3} \mathrm{H}_{6}$, at three different strain rates as predicted by the detailed model. The flames are at atmospheric pressure and an inlet temperature of $300 \mathrm{~K}$ with the twin jets composed of an $n$-dodecane/air mixture at $\phi=0.7$. 


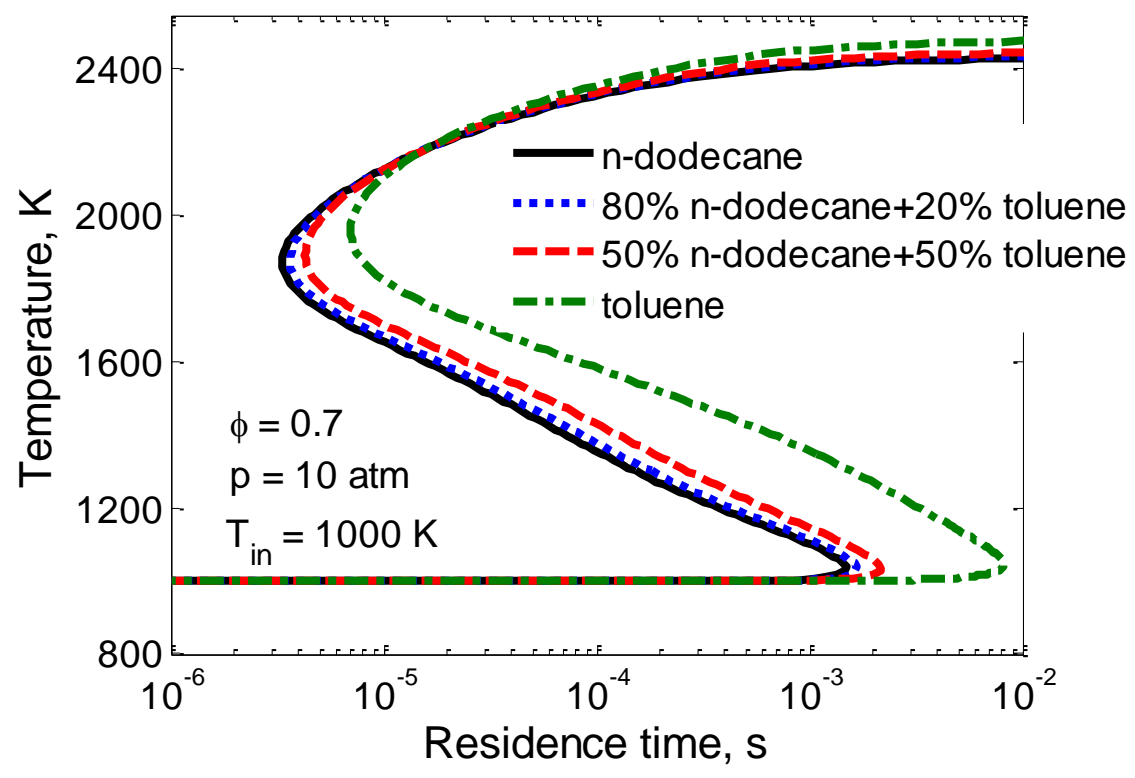

Figure 7. $S$-curves in PSR for $n$-dodecane, toluene and their mixtures at pressure of 10 atm, $\phi=$ 0.7 and inlet temperature of $1000 \mathrm{~K}$, calculated with the detailed JetSurF 2.0. 


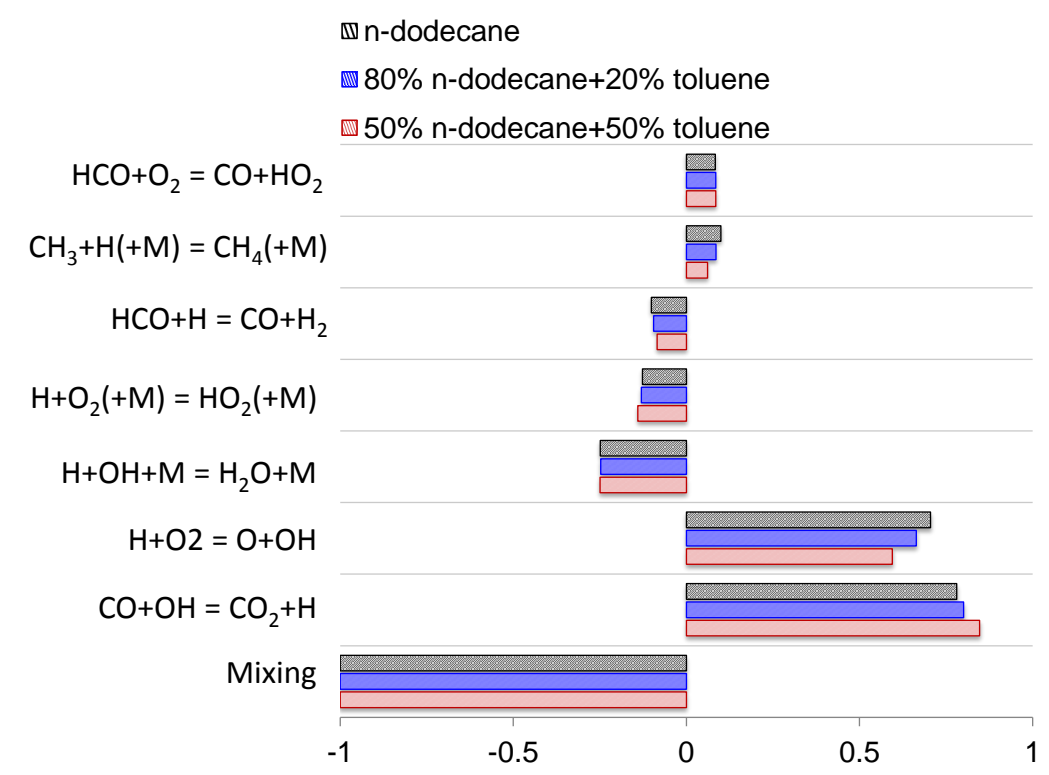

(a) Bifurcation index at extinction

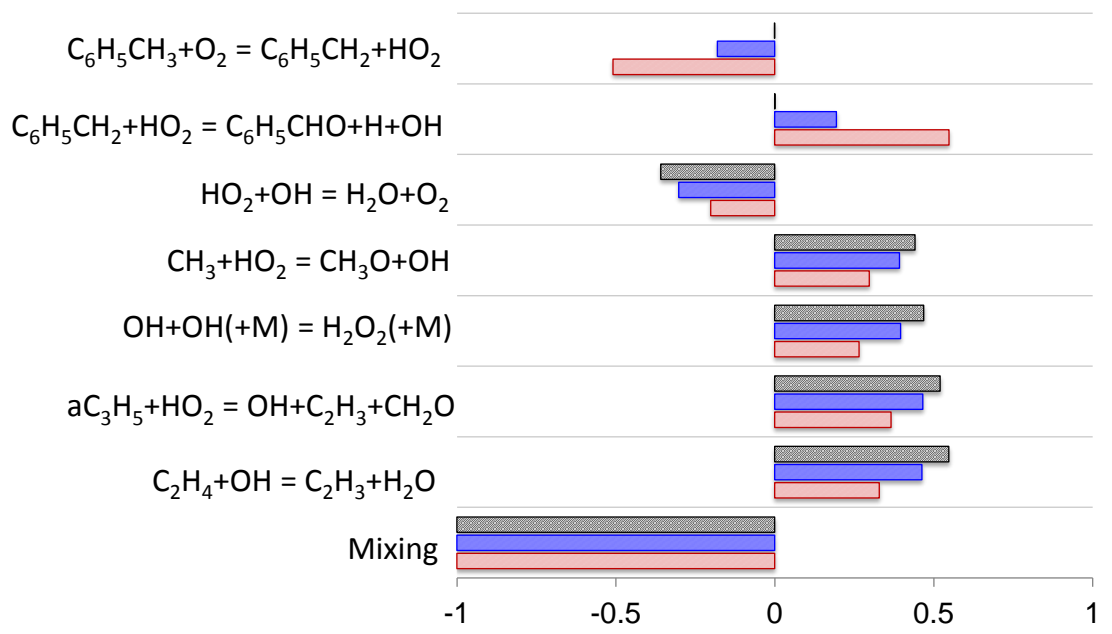

(b) Bifurcation index at ignition

Figure 8. Largest, ranked bifurcation index of reactions computed for extinction (a) and ignition (b) states on the PSR $S$-curves of Fig. 6, comparing pure $n$-dodecane with two binary mixtures of $n$-dodecane and toluene. 

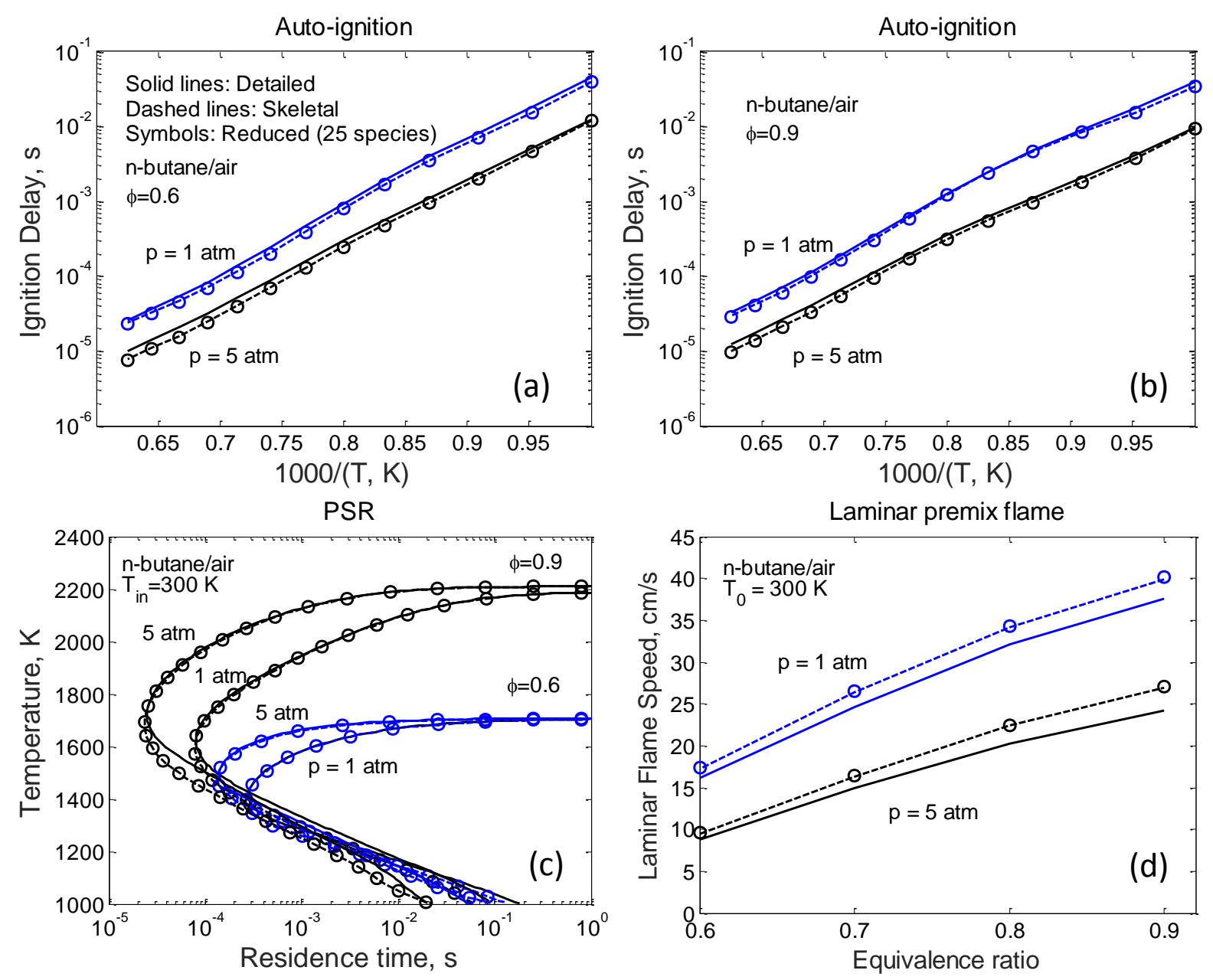

Figure 9. Ignition delays, PSR extinction and laminar flame speed for $n$-butane/air mixtures at equivalence ratios of $\phi=0.6-0.9$ and pressures of 1 and $5 \mathrm{~atm}$, calculated with the detailed, skeletal and reduced models. 


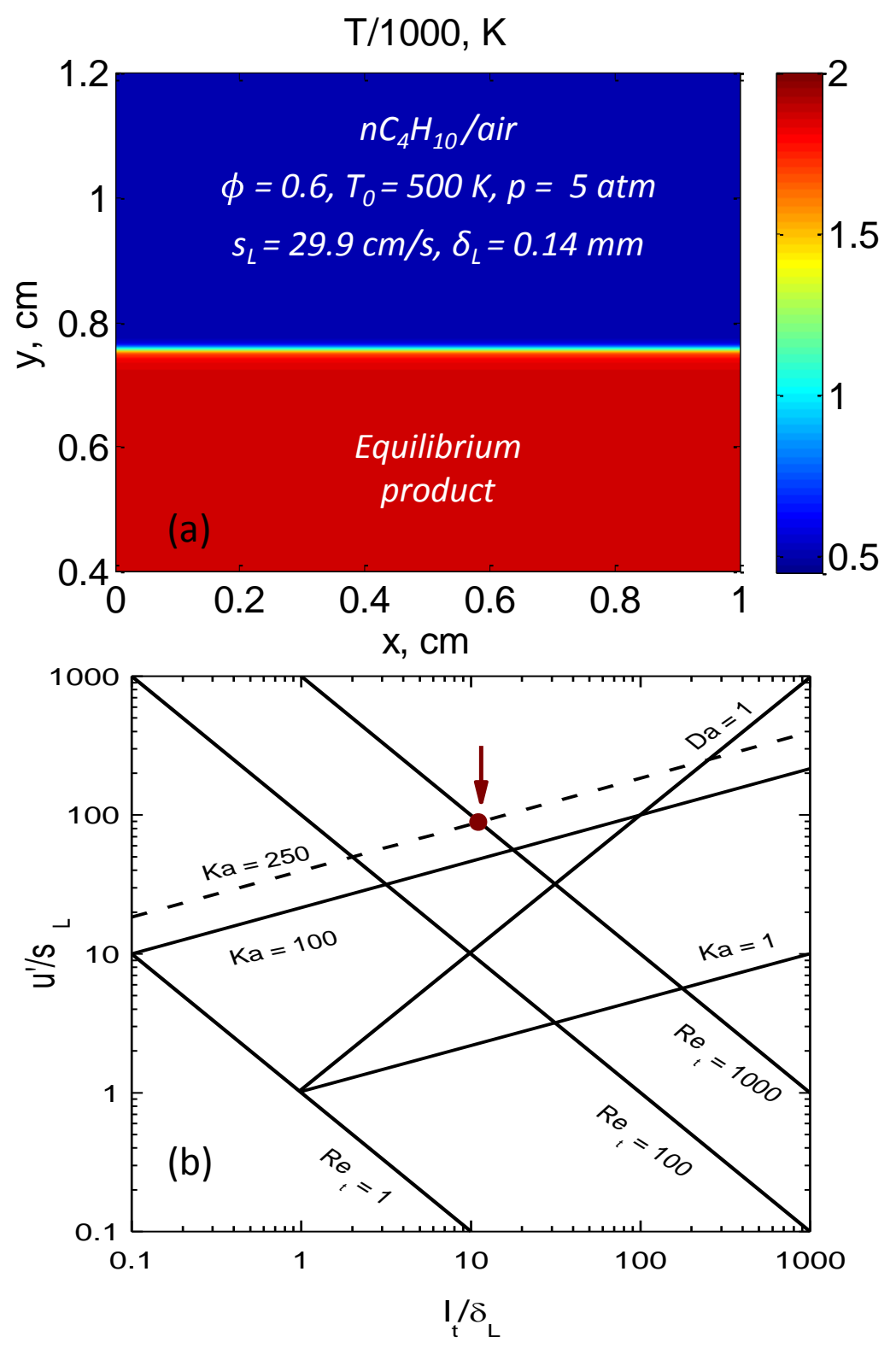

Figure 10. (a) Initial temperature isocontour for the 2-D DNS of $n$-butane/air, and (b) location of the DNS case on the Borghi diagram $\left(K a=250, R_{t}=1000\right)$. 

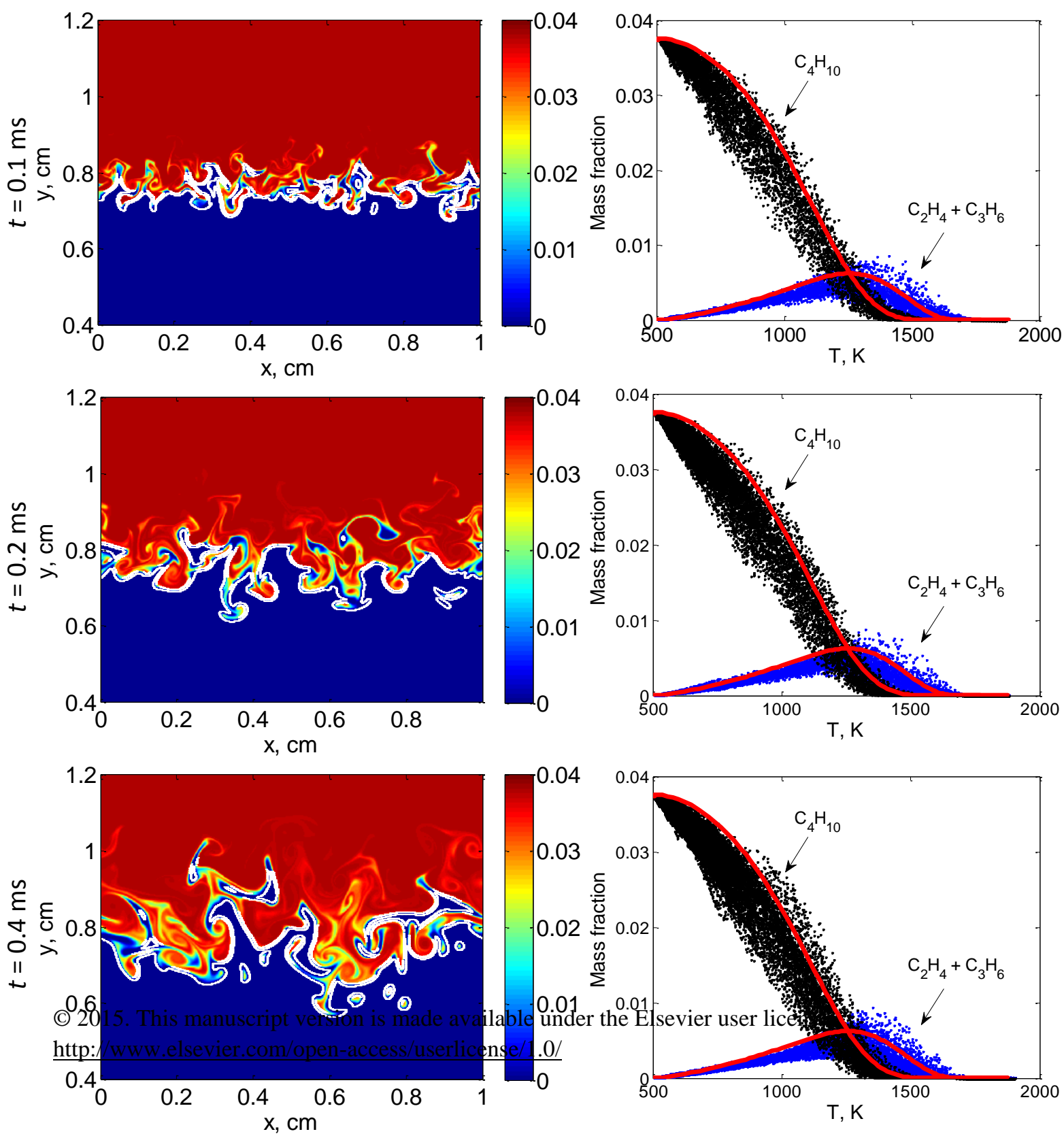

Figure 11. Left panels: Isocontour of fuel mass fraction (red: fresh mixture, blue: hot products), and right panels: scatter plots of mass fractions of fuel and primary cracking products vs. temperature, for DNS of a turbulent premixed flame of $n$-butane/air at different time instances. The white isolines on the left panels show the flame zone identified using CEMA. The solid lines on the right panels are solutions from 1-D steady state premix flame with the same fresh mixture condition as that in the DNS. 